\title{
The Issue of Solid Household Waste Management in the Mateba Health Area (Ngaba), Kinshasa, DRC
}

\author{
Cush Ngonzo Luwesi ${ }^{1 *}$, Joel Kafumbi Katsiatsia ${ }^{2}$ and Claudine Kandi Mikumba ${ }^{3}$ \\ ${ }^{1}$ Associate Professor, Faculty of Economics, West Africa \\ ${ }^{2}$ Chef's work, Higher Institute of Medical Techniques Mary Queen of Peace Kenge, West Africa \\ ${ }^{3}$ Assistant, Institute of Medical Technology Marie Queen of Peace Kenge, West Africa \\ *Corresponding author: Cush Ngonzo Luwesi, Associate Professor, Faculty of Economics, West Africa
}

\begin{abstract}
ARTICLE INFO
Received: 幽 May 06, 2019

Published: May 24, 2019

Citation: Cush Ngonzo Luwesi, Joel Kafumbi Katsiatsia, Claudine Kandi Mikumba. The Issue of Solid Household Waste Management in the Mateba Health Area (Ngaba), Kinshasa, DRC. Biomed J Sci \& Tech Res 18(2)-2019. BJSTR.
\end{abstract} MS.ID.003136.

Keywords: Dirty Hand Disease; Household; Public Cleanness; Solid Waste; Waste Management; Dishes Solid; Public Insalubrity; Hand Disease Rooms; Household
ABSTRACT

The rapid urban $\mathrm{n}$ population growth and the uncontrolled urbanization most mega in African cities-have led to the mismanagement of household wastes and reted socio-economic and health problems. From the mite population sensitization behavior is changing and several sanitation activities Organized in small square no's significant improvement has been Recorded to date in the behavior of the citizens and the key of their cities. The study Conducted in the Mateba health has are of Kinshasa City avocation to the end the de factors that allowed such mismanagement of solid waste at household level. A household survey and interviews enabled data collection from about 384 in inhabitants. Results of the stud y reveal that Households are bigger producers of waste due to the m o Lack of will there, waste bins and centers of transit. These factors disclose the absence of an effective policy with regard to waste management in the country. The institutionalization of waste mismanagement at different scales, has multiple repercussions we dirty hand diseases that include malaria, typhoid worm, cholera, diarrhea, to name a FEW goal diseases. Consequently, there is a great need for ad hoc Adopting clearer polished and affecting subsequent resources to improve waste management in the DRC and Kinsh in his City in general, and the health Mateba area, particular.

\section{Summary}

The rapid growth of the urban population and uncontrolled urbanization or mastered for years the major cities of Africa are the basis of my household waste management and problem attics socio-economic and health related there. In spite of organized sensitization in small neighborhoods, the behavior of the population seems not be conducive to the consolidation of the city. The study conducted in the Mateba Health Zone of the City of Kinshasa aimed to identify the factors that favor the mismanagement of solid household waste. A household survey and interview technique made it possible to collect data with 384 inhabitants. The results of the study revealed that households are major producers of waste. The lack of money, bins and transit centers are at the root of this bad waste management. These factors reveal firstly the absence of an effective policy on waste management in our country, and the other parts in stitutionnalisation of poor waste management at different scales. This which in fact is at the root of many repercussions in terms of diseases sales of hands including malaria, typhoid fever, cholera, diarrhea. Therefore, the adoption of an ad hoc policy clear on this matter may only be removed and the allocation of substantial resources to it ever be strongly recommended for improved waste management DRC and the City Province E Kinshasa in general and the Mateba health area in particular.

\section{Introduction}

The man is the main virus its environment and, Since the 70-planet earth is facing the problem of pollution by waste from activities [1]. This problem is widespread with technological progress and economic development, which has led ows immeasurable amount of waste. The present and future generations suffer consequences and possible negative effects in the medium 
and long terms of the arrow toxic and other pollutants on the environment [2]. Thus, toxic waste management is denos day a real public health problem in African cities. A report on the disposal of solid waste (Table 1) the first the problem of accumulation in Garbage Metropolitan cities in Africa in terms of the rapid increase in urban population and excessive expansion of urban space. This uncontrolled and uncontrolled urbanization of major cities Africa is the basis of problem of household waste management [3]. Face to these unthinking acts of recklessness and égoïs me peers, the scientists are looking for nowadays different ways to recycle waste affix $\mathrm{n}$ to support the resource consumption savings that will took place. They resort to means e landfills, incineration and d e storage to deal with the clutter of household waste and toxic industrial which causing pollution planet earth [4].

Table 1: Distribution of respondents by marital status.

\begin{tabular}{|c|c|c|}
\hline Marital status & Frequency & Percentage \\
\hline singles & 84 & 22 \\
\hline Married (s) & 70 & 18 \\
\hline Widow (widowed) & 36 & 9 \\
\hline free Union & 194 & 51 \\
\hline Total & 384 & 100 \\
\hline
\end{tabular}

In some corners of the city of Kinshasa, the European Union has placed garbage cans and garbage dumps publics that generated significant Advanced for sanitation of the environment. Unfortunately, these efforts by the international community have gone up in smoke because the city authorities have unable to continue EU action by building garbage cans in several parts of the capital [5]. Thus, the bins are abandoned to their fate exp dare less waste non evacuated Advantage explodes. What makes the insalubrity is far from being conquered in Kinshasa following the Kinois human behaviors but also the lack of a clear organization in this matter by the political authority [6]. The same observation is made in the health zone of Ngaba in Kinshasa, precisely in the health area of Mateba where the management of household waste poses serious problems not only sanitary but also environmental. This population continues to pollute its environment by discharging solid and liquid waste [7]. This finding is préoccup ant at the highest point and shoot mint to the next question: what are the factors favoring the poor waste management in the health area Mateba? Is the population aware of the consequences of poor solid waste management on their health? The objective of this study is therefore to determine the factors favoring the mismanagement of solid household waste in the Mateba health area. and assess the awareness of this population about the consequences of this mismanagement. To achieve this goal, the following specific objectives have been pursued:

a) To enumerate the frequency of waste disposal per week in households;

b) Identify factors related to poor waste management within the afford mentioned health area; and c) Identify the consequences of this mismanagement.

\section{Literature Paper}

The literature one Abound ant unhealthy reveals a ns of its diversity many public health problems related to hygiene and sanitation of the environment, both at the national level [8]. Current statistics show that the amount of waste emitted by the inhabitants of our planet is 4 billion tones per year [8]. The total amount of waste generated in the pays UE European Union (EU-28) amounted to 2.503 million tones 2014 per year or all of their economic activities and household re s, and to some extent, to the size of the country's population [9]. However, the average production of municipal waste per person has steadily decreased in the European Union (EU) since 2007, falling below its level in the mid-1990s. It rose from $527 \mathrm{~kg}$ in 2002 to $475 \mathrm{~kg}$ in 2014, a decrease of $10 \%$ [10]. The Africaines cities will be the most exposed to effets related to poor evacuation of waste and sewage. Solid and liquid waste management conational a real problem for e Tet authorities public health policy and management [11]. The demographic explosion and the problem of household waste management are linked to the higher level of urban agglomerations, following the lack of a legislative, administrative and financial policy for good household waste management [12].

For example, the exhibition generalized wastewater (Table 2) and excreta in urban areas of Niger is as much a worrying problem, particularly where the population is dense and the locals sometimes retain rural habits in the matter (defecation in the open, rejection dishwater, etc.). In the city, garbage is little collected and piled in the streets and garbage dumps. In terms of liquid sanitation, the city has no sewage system [13]. Kinshasa is facing a recurring problem of waste management \& remediation and policy in Congolese cities. No one urbanized neighborhoods s poorest of the capital give the face of a city abandoned to its sad fate: no public garbage cans, no drainage channels, etc. [14]. Un modest home produces about $3 \mathrm{Kg}$ solid household waste and $30 \mathrm{Kg}$ liquid waste every day. An area ant counted six avenues of 200 plots do off Product 28 ra. K 800 g of solid waste and $288 \mathrm{~m} 3$ liquid waste every day [15]. In the neighborhood are situated near the central market in Kinshasa, like the Ngbaka neighborhood, everyone tries to get rid of household waste in its own way. For consistent, piles of garbage cluttering public places and are a real bomb retarment of health of populations nearby, because the smell coming out of these filth seems not to disturb the small shops and street restaurants commonly called "Malewa" [16]. Thus, an August 24, 2010, European Union launched the work of fight against unhealthy creating a project to remove the waste and filth called PARAU. But after the transfer of this project to the Congolese State, the latter has shone by his incompetence were able disposal of garbage and dumps publics, in both urban and rural areas, at the national level and the provincial. From then on, s voices in some municipalities, like Bandalungwa, Kasavubu, Lingwala, Kinshasa Kintambo or express discomfort face the withdrawal from the European Union and the effects that generate these mountains 
of rubbish [17]. Insufficient sanitation is responsible for nearly 74 percent of all cases of disease in DR Congo, including parasitic infections, diarrheal infections, acute respiratory diseases and other communicable diseases. Many of these diseases, including cholera, red diarrhea and typhoid remain endemic and epidemic take paces (Secretariat General for the Environment [18] and also took home in the most unsanitary administrative entities: the relaxation of weeding activities, pest and rodent control recognitions the proliferation of insects and rodents, and more are diseases such as malaria, schistosomiasis, sleeping sickness, plague, onchocerciasis and filariasis [19].

Table 2: Distribution of respondents by level of education.

\begin{tabular}{|c|c|c|}
\hline Level of Education & Frequency & Percentage \\
\hline No level & 48 & 12 \\
\hline Primary & 23 & 6 \\
\hline Secondary & 220 & 57 \\
\hline Higher and University & 93 & 24 \\
\hline Total & 384 & 100 \\
\hline
\end{tabular}

\section{Materials and Methods}

\section{Description of the Environment of Study}

Our study took place in the health area of Mateba which is one of the health areas of the Ngaba Health Zone, in the city of Kinshasa province. It has a population of 25,891 [20]. The population is mostly young, with an average age of thirty years. The health area of Mateba is inhabited by several national tribes including Kongo, Swahili, Luba, Yaka and some expatriates including Congolese Brazzaville, Angolans, Lebanese and Chinese. The population accesses REGIDESO's drinking water through a distribution network consisting of new plastic pipes and old metal pipes that cause uncontrollable leakage, sometimes making the environment very unhealthy.

Table 3: Frequency of evacuation of garbage cans

\begin{tabular}{|c|c|c|}
\hline Number of Times (per week) & Frequency & Percentage \\
\hline Two times & 81 & 21 \\
\hline Thrice & 242 & 63 \\
\hline Many times & 61 & 16 \\
\hline Total & 384 & 100 \\
\hline Total & 384 & 100 \\
\hline
\end{tabular}

The Christian religion is the most practiced religion. The most spoken languages are Lingala and Kikongo. The low purchasing power forces the population to subsistence activities, namely: small businesses (shop sales, telephone booths, the display of bread and others, street vendors), market gardening, technical workshops (garages, carpentry, masonry) (Table 3) These activities occupy about $70 \%$ of the population considered active. Unemployment mainly affects young people, leading to an upsurge in juvenile delinquency through organized gangs commonly known as "Kuluna" that affect all health areas in search of easy gain. In addition, large avenues called "Directions" are transformed to small day and night markets to allow the survival of the population. The behaviors associated with poverty such as vandalism, the presence of many street children and girl mothers and prostitution are very remarkable among the inhabitants of this population.

\section{Sampling and Technique Collection of Donations}

The sample in this study is simple random probability. Its size was calculated by the Fisher and amounted to 384 men and women living air health and Mateba in Ngaba health zone. The data collection took place during the period from April 15 to July 15,2015 . Respondents were questioned impromptu as they went about their housework. In some cases, the investigator took care to get an appointment at preferable before administering the questionnaire or be interviewed.

\section{Selection Criteria}

The researcher has established criteria the following before re all included in the SAMPLE about it will study:

To be a man or woman of a household in the health area Ateba million in the Ngaba area of health;

a) Being present during the jars of the investigation;

b) Freely accept to participate in the study; and

c) Having the ability to meet unary interrogate in French.

\section{Criteria Exclusion}

Was supposed to be excluded from the sample, t out about who lives would the health area for less than a week, or do not speak the French has langue, much less the Lingala.

\section{Technical Analysis Data}

The analyzes were essentially descriptive based on the calculation of the frequencies. The data has been tabulated to facilitate the calculation of frequencies. Trends were detected based on the following formula:

$$
f(\%)=F_{O} / F A^{*} 100 \quad \text { [Equation 1] }
$$

Or,

$\mathrm{f}(\%)=$ Relative frequency in percentage

$\mathrm{FO}=$ Frequency observed

$\mathrm{FA}=$ Expected frequency

\section{Results of Analysis}

\section{Profile of Respondents}

The results in Figure 1 reveal the majority of respondents were aged between 30 and 39 years (41.1\%), followed by s of those whose age ranged from 40 and 49 years old ( $19.0 \%$ ), 50 and 59 years old ( $16.1 \%$ ) and 20 and 29 years old ( $15.4 \%$ ). The surveyed 
older (59 years old and over) represented only $8.3 \%$. In terms of gender distribution, $53 \%$ of respondents were female while $47 \%$ were female and male (Figure 2). The issue of solid household waste management in the Mateba health area (Ngaba), Kinshasa, DRC. Households made up of more than 6 persons were the most numerous (58\%), followed by those composed of 4 to 6 people (25\%). and finally, those under 4 (17\%) (Figure 3) Households made up of more than 6 persons were the most numerous (58\%), followed by those composed of 4 to 6 people $(25 \%)$ and finally, those under 4 (17\%) (Figure 3). As for the factors favoring the mismanagement of waste, the (Table 4) indicates that the absence of transit dumps, the lack of public trash s lack of money, and the absence of garbage collectors, are among the most recurrent factors advanced by the respondents, representing respectively $31,26,22$ and $21 \%$ of the sample. Finally, asked about the consequences of the non-discharge of their household waste, e s respondents have ineluctably indicated that diseases hands venues such as typhoid fever $(32 \%)$, malaria $(21 \%)$, cholera $(20 \%)$, diarrhea $(13 \%)$ and schistosomiasis (6\%) underpins related to unhealth and $8 \%$ of respondents confirmed all these results (Table 5) .

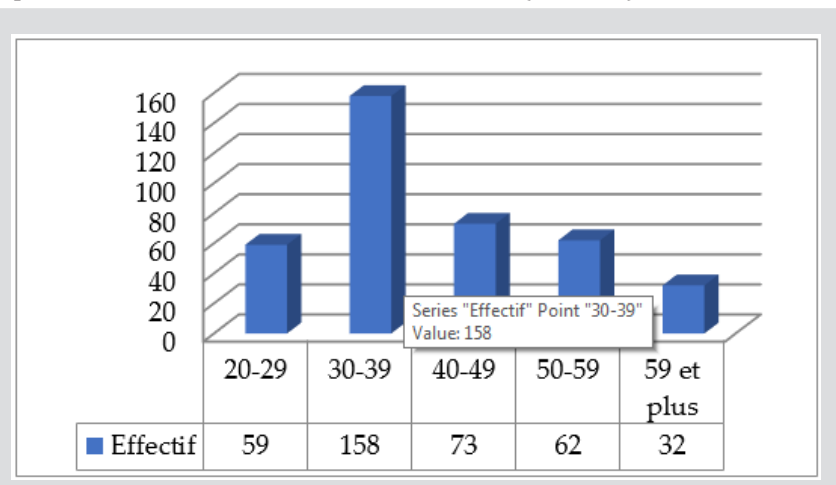

Figure 1: Distribution of respondents by age.

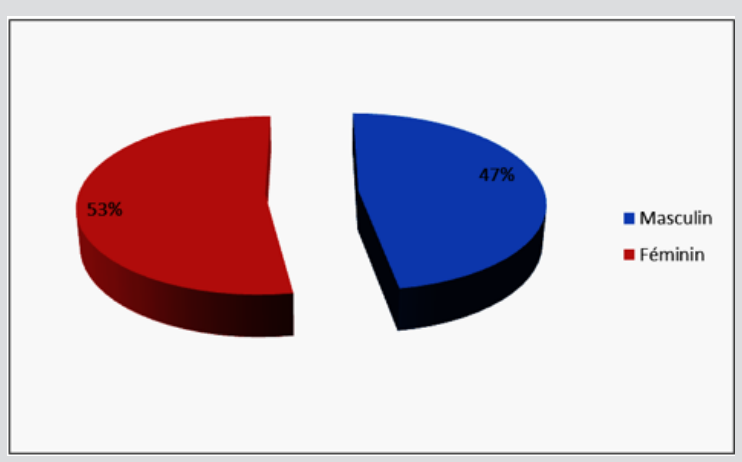

Figure 2: Distribution of respondents by gender.

Table 4: Factors promoting poor waste management

\begin{tabular}{|c|c|c|}
\hline Postman & Effective & Percentage \\
\hline Lack of public trash & 100 & 26 \\
\hline Absence of garbage collectors & 80 & 21 \\
\hline Lack of money & 84 & 22 \\
\hline Lack of transit discharges & 120 & 31 \\
\hline Lack of public trash & 100 & 26 \\
\hline Total & 384 & 100 \\
\hline
\end{tabular}

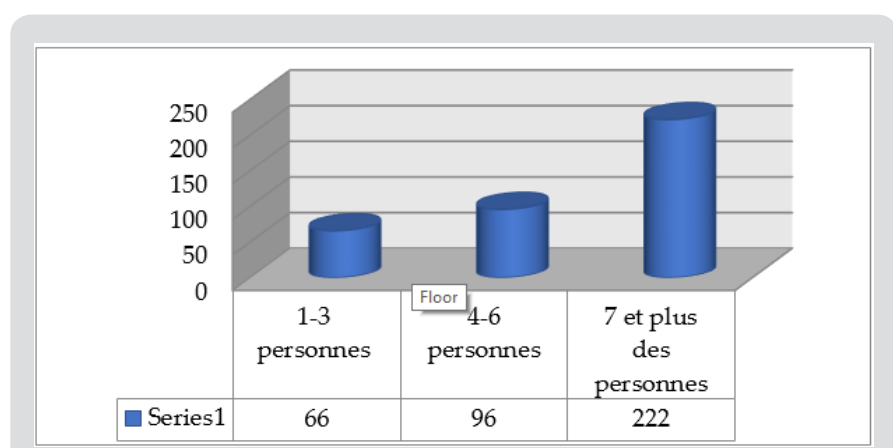

Figure 3: Size of households.

Table 5: Factors favoring poor waste management.

\begin{tabular}{|c|c|c|}
\hline Postman & Effective & Percentage \\
\hline Typhoid fever & 123 & 32 \\
\hline Malaria & 81 & 21 \\
\hline Cholera & 77 & 20 \\
\hline Diarrhea & 50 & 13 \\
\hline bilharzia & 23 & 6 \\
\hline To us the above factors & 31 & 8 \\
\hline Total & 384 & 100 \\
\hline
\end{tabular}

\section{Discussion of Results}

\section{Discussion on the Disposal of Household Waste}

The results of this study showed that the majority of our respondents confirm that they emptied their trash cans 3 times a week, ie $63 \%$ of the sample, $21 \%$ empty them twice a week and $16 \%$ do so several times a week. These results provide ample evidence that households are among the major producers of waste. These results coincide with those found in several studies around the world [21] stated that today man has become a mass consumer and therefore a major producer of waste [22] notes that in 2014, the total volume of waste generated in the EU-28 by all economic activities and households was 2. 503 million tonnes; this is the highest volume ever recorded in the EU during the period 20042014. As may be expected, the total volume of waste produced is related to some extent to the population and the country's economic size. The study conducted an analysis of the amount of waste produced, depending on the size of the population. The high quantities of waste generated in some of the smaller EU Member States can be clearly seen, with a particularly high value for Bulgaria, where on average 24.9 tonnes of waste were produced per capita in 2014, five times the 4.9 tonnes of waste produced on average per capita [23].

\section{Discussion on Factors Favoring Mismanagement of Waste}

Among the factors favoring the poor waste management, this study found the following factors -after the lack of public garbage (26\%), the absence of garbage collectors (21\%), the lack of money $(22 \%)$ and the absence of transit dumps (31\%). This situation of waste management is really worrying in the Democratic Republic 
of Congo in general and in the city of Kinshasa in particular. Indeed a city of Kinshasa has received support from the European Union to improve the management of waste is s. Transit dump centers have been built in some neighborhoods with a clear waste disposal policy. Unfortunately, the Mateba district is among those who have not benefited from this support from the European Union. But these days, the i no longer exists Public trash cans for garbage disposal nor are transit centers [23]. Some associations and individuals have created a garbage collection job that involves housekeeping with trolleys to collect them. Some pass each day, others have a weekly pickup schedule.

To take advantage of these services, you must either pay money directly during the pick-up or subscribe for a monthly payment country where over $60 \%$ of the population is of unemployed not everyone has these opportunities [24]. Although these associations have made garbage collection a lucrative job, they end up like the rest of the population by abandoning them in inappropriate places where they pollute the environment, resulting in total insalubrity; attracting flies and giving off odors that carry a lot of risk for the population. The major problem is that there is no clear and effective waste management policy at the national, provincial and municipal levels $[2,25]$ notes that the population explosion and the problem of household waste management are linked to the higher level of governance of urban agglomerations and the lack of a legislative, technical, administrative and financial policy for good management of urban areas. household waste [14] also considers that the modest technical and financial means alone would not suffice to justify the state of insalubrity in which African cities are located. The mismanagement of waste in the city would thus be the results of multiple and diverse causes related to the characteristics of the habitat. He would not therefore, it is not possible to solve the problem of poor household waste management if actions to improve the quality of socio-economic housing are not carried out [26].

\section{Discussion on the Consequences of Mismanagement of Waste}

Regarding the consequences of poor waste management, our respondents have reconn u ineluctably that poor waste management contributes to the deterioration of household health. Hand-room diseases such as typhoid fever (32\%), malaria (21\%), cholera (20\%), diarrhea (13\%) schistosomiasis (6\%) and others (8\%) are more and more related to poor waste management household. It is true that the insalubrity causes several harmful consequences on the human as well as animal health and even on the environment. However, it should be affirmed as [1] that man is the main virus of his environment. It is therefore not enough to recognize the existence of consequences related to insalubrity but rather to know how to prevent them [13] reveals that the consequence of mismanagement is environmental pollution including degradation of the living environment and human health hazards. Of course, in Burkina Faso, there is no specialized pollution service to accurately determine the proportion of pollution in a particular disease.
However, all actors agree that an unhealthy environment promotes the development of several diseases. According to Yacouba Ouédraogo [13] the smoke of the burned garbage is very harmful for the health. "When the gas of this smoke comes into contact with the eyes, it becomes moist and becomes like acid in the body." This state of affairs can also cause individuals, respiratory diseases such as asthma, rhinopharyngitis (the respiratory tract that leaves the nose to the lungs can swell under the effect of toxic gas.

According to Kinda (2012), Wastewater is an Unhealthy Environment for the Propagation of Harmful Insects: According to the Program National Environment (PNE) are the wastewater discharged by residents mix with rainwater so that in winter and sometimes long after its end, the gutters provide a mosquito conducive to proliferation medium.

And WHO (20 17): Of all the insects that transmit diseases, Mustique is the most dangerous.

In fact, the mosquito is at the origin of the transmission of malaria, dengue, yellow fever which together are responsible for several million deaths. That is to say that waste denature the living environment to the delight of harmful insects. These contaminate humans by direct consumption and or by posing for example on feces and then transmit the infectious agents by posing on the food products. For example, men contract debilitating and deadly diseases such as typhoid fever, dysentery, cholera $[2,18]$ argues that poor waste management results in the proliferation of several infectious diseases such as diarrhea, cholera, amoebic dysentery, typhoid fever and malaria [8], adding that of our human waste days are the leading cause of water pollution. Releases are often sent to landfills and this is where the high-water contamination begins [23].

\section{Conclusion}

In conclusion, insalubrity is a real health problem in African cities in general and Kinshasa in particular, as noted by UNDP [7]. The pollution is not only a visual or olfactory discomfort but now the major environmental risk to health worldwide. According to the World Health Organization (WHO), e is the daughter and the untimely death of 7 million people each year worldwide, including more than $40 \%$ in Africa. It is therefore not surprising to see the multiplication of episodes of diarrheal diseases and cholera in the city of Kinshasa , a city where the water distribution channels that circulate there are for the most part in an advanced state of disrepair , and garbage cans and public dumps are almost abandoned to their plight. The study conducted at the Mateba health area (Ngaba) in its Kinsha, e shown that the majority of households in the sample empty their bins at least 2 times a week. These results provide ample evidence that households are among the major producers of waste. Thus, then it rains, biodegradable wastes are mixed with water and product of organic carbon, which can lead to acid rain are.

Thereafter, acid rain polluting the different water sources a commitment utilized es by the people, including rivers, lakes, 
marshes and puts. In addition, these are the element passing through the art waste seeps into the ground until reaching underground and pollute groundwater. As a result, sources of fresh water are contaminated with Lourdes metals, are products of e cleaning and other toxic waste. Moreover, the analysis reveals the absence of an effective policy of coordination in the field of waste management in our country, due to lack of financial means and trash publics the lack of garbage and landfills transit. As a result, most landfills are in the open air which is dangerous for the health of the populations. Th is bad policy for the reorganization of an environment in DRC corollary, the institutionalization of a LUBRITE ins and lack of hygiene at different levels of the management of public affairs. it is actually the basis of multiple impacts in term $\mathrm{s}$ of diseases die nomics including those from the theater: malaria, typhoid fever, cholera and diarrhea.

\section{Recommendations}

The adoption of a clear ad hoc policy on waste management cannot be dismantled and the allocation of substantial resources should be strongly recommended for the improvement of waste management in the DRC and hygiene. in the City of Kinshasa Province. The e attitude change s population facing the unsanitary conditions and the lack of sanitation in the city of vary promote the adoption of a behavior and hygienic to end fighting against its animateurs. The population must strive so little to clean up its environment and reach deals finally waste materials, both solid and liquid are. Waste treatment means of art funds and considerable material and the possibility of recycling some of these materials for useful purposes. It is therefore the authorities public of matter the resources and equipment necessary for the provision of the population to assist him to get involved in waste management, in terms of art homemaker has ges to that of the city.

\section{References}

1. Kiyombo (2013) Hygiene and health of the environment. Kinshasa: Division of Community Health, ISTM Kinshasa, Dem ocratique Congo.

2. Dassou A (2006) Categorization of solid waste. Paris: Hope Africa, France.

3. André H (2002) Management of hospital solid waste. UTC.

4. Kazika A (2014) The management of solid waste and filth in big cities! Problem of lack of responsible citizenship and civic education, the voice of young people.

5. (2017) Media Congo, Insalubrity in Kinshasa: the mountains of filth, source of various infections. Rubrique health published.

6. Kakesa T (2012) The persistence of insalubrity in Kinshasa: from coercion to conscientization. A communication approach for behavior change. Bachelor's degree in social communication, marketing and public relations option. Kinshasa: Catholic University of Congo, Dem ocratique Congo.

7. (2009) UNDP, United Nations Development Program 2009. Clean urban environment. Kinshasa: UNDP Secretariat, Democratic Republic of Congo.

8. Stravinskaite A, Gonzalez JP (2012) Impact of waste production on the environment, Learn online.

9. Eurostat (2017) Waste statistics.

10. (2014) Eurostat, Statistical Office of the European Union 2014. Production and treatment of municipal waste in the EU (in kg per person).

11. Adam (2002) Evacuation of excreta in the said city, Yaoundé, Cameroon. Paris: Africa hope, Republic Translation aise.

12. Carballo J, Reis VB (2012) Impact of waste production on health. Learn online

13. Kinda B (2012) Urban waste pollution A real public health problem, the event.

14. Lokombe P (2010) Kinshasa: Insalubrity, solid waste management on the agenda. PATCOX21.

15. Mbuyi N (2013) Mismanagement of household waste at the root of a public health problem in the Ngbaka district. Kinshasa: Human Rights of Journalists, Media Rights, Dem ocratique Congo .

16. (2014) MINISANTE, Ministry of Health 2014. Annual Report of the Central Bureau of the Health Zone. Kenge: Central Office of the Health Zone Kenge, Dem ocratique Congo.

17. (2008) WHO Sustainable waste management and urban sanitation. Geneva: World Health Organization.

18. (2017) WHO, World Health Organization 2017. Diseases with vector transmission. Geneva: Secretariat of the World Health Organization (WHO), Switzerland.

19. (2016) Okapi Radio. Waste management in Kinshasa.

20. (2016) Okapi Radio. RATPK.

21. (2001) General Secretariat for the Environment 2001. Report on insalubrity in the cities of the DRC. Kinshasa: Democratic Republic of Congo.

22. Terica K (2011) DRC: How to overcome the scourge of unemployment?.

23. (2012) Project hygiene - sanitation of the city of Maradi (PHAM). Annual Activity Report 2012 Niamey: Office of the Mayor of the town of Maradi, Niger.

24. Yasmin (2002) Initiation to methods in the social sciences. Kinshasa: ISTM Kinshasa, Dem ocratique Congo.

25. Yawidi JP (2009) Trial of society. Kinshasa: National Pedagogical University (UPN), Democratic Republic of Congo.

26. Yenamawu AN (2010) Problem of household waste management in the city of Kinshasa, case of the municipality of Masina. Master's thesis in Agricultural Sciences. Kinshasa University of Kinshasa, Dem ocratique Congo. 


\section{ISSN: 2574-1241}

DOI: 10.26717/BJSTR.2019.18.003136

Cush Ngonzo Luwesi. Biomed J Sci \& Tech Res

(c) (P) This work is licensed under Creative

Submission Link: https://biomedres.us/submit-manuscript.php

$\begin{array}{ll}\text { BIOMEDICAL } & \text { Assets of Publishing with us } \\ \text { RESEARCHES } & \text { - Global archiving of articles } \\ & \text { - Immediate, unrestricted online access } \\ & \text { - Rigorous Peer Review Process } \\ \end{array}$

